\title{
RESENHA
}

Marilda Alves Adão Carvalho ${ }^{1}$

\section{WILLIAM LABOV E O REALISMO SOCIOLINGUÍSTICO}

\author{
FIGUEROA. Esther. Part Two: William Labov and Sociolinguistic Realism. In: \\ . Sociolinguistic metatheory. Oxford: Pergamon, 1994.
}

Em seu texto, inicialmente, Figueroa se refere à base estabelecida por Labov para a Sociolinguística, a qual incide em um ponto de vista e um método pelos quais o desenvolvimento dos sociolinguistas sofre influências. A linguística laboviana, na visão dessa autora, é sinônima de sociolinguística em muitos círculos linguísticos e mesmo com o enfraquecimento dessa tendência, não se pode negar a influência de Labov no desenvolvimento da sociolinguística.

Remetendo-se à ideia de sinonímia entre linguística e sociolinguística, Figueroa ressalta que, para Labov "a Sociolinguística é um uso equivocado e redundante. [...]" (Labov, 1972a, p. 183). Equivocado, porque de algum modo implica a existência de distinção entre a sociolinguística e a linguística e redundante por implicar na não possibilidade de uma linguística que desconsidere o aspecto social da linguagem.

Para Labov, a sociolinguística é linguística propriamente dita "o estudo geral da estrutura da linguagem" (Labov, 1975, p 77) e, assim sendo, seu estudo deve ser realizado no contexto social da comunidade de fala. Para Figueroa, Labov acaba por resistir à implicação da diferença da sociolinguística em relação à linguística, portanto, mantendo a concepção de que a sociolinguística é linguística, ela discute a rejeição de desse linguista à ideia e/ou à sugestão de se considerar a sociolinguística como uma área interdisciplinar (tal qual visão de Hymes). A autora salienta que Labov não nega a contribuição de outras áreas para o estudo da linguística, mas, ele argumenta o quanto o formalismo estreito é prejudicial ao estudo da língua, enfatizando que a linguística pode ser reforçada com conhecimento de fisiologia, com o uso do processo social e cognitivo da linguagem (Labov, 1975, p 130). Na verdade, sua preocupação incide no sistema linguístico tomado numa perspectiva puramente linguística, visto que seu foco são os fatos linguísticos, os quais podem estar ou não relacionadas a fatos sociais específicos, que, de acordo com Figueroa, torna evidente a contradição do autor quando nega o caráter interdisciplinar da sociolinguística.

Nesse sentido, Figueroa fala da dissociação feita por Labov entre a Sociolinguística, a sociologia da linguagem, a etnografia da fala e sua própria abordagem, na qual ele propõe o estudo da estrutura e da evolução da língua, entretanto, interno ao contexto social da comunidade de fala. O interesse dele é, em especial, certo tipo de macrolinguística, para a qual o lugar da linguagem não está

\footnotetext{
${ }^{1}$ Professora da Universidade Estadual de Goiás. E-mail: marildaf3@yahoo.com.br.
} 
no indivíduo, mas em algum tipo de ordem social (a comunidade de fala). Assim sendo, ele ajusta seu trabalho conforme as definições da linguística pura em seus tópicos de interesse (Fonologia, Morfologia, Sintaxe e Semântica), deixando de lado outras questões.

Figueroa aponta que a Sociolinguística laboviana é o estudo da linguagem associada à exterioridade linguística (cf. LABOV 1972a), embora ela apresente críticas à inserção do plano extralinguístico na língua, em virtude de, em seu ponto de vista, o estudo do contexto social não poder ser interpretado como estudo funcionalista e nem confundido com noções culturais, sociocognitivas, interativas ou fenomenológicas desse contexto. Para ela, a sociolinguística não é uma teoria da fala, mas o estudo da língua por aquilo que ela revela sobre a estrutura linguística (langue), o que deixa evidente sua visão de língua no plano micro e não macrolinguístico, como é o caso de Labov, para o qual língua e contexto social são entidades separadas, e a sociolinguística correlaciona fatos linguísticos a fatos sociais.

Para a autora, há três realismos, isso metateoricamente, na formulação da sociolinguística de Labov: a) o realismo metafísico, que se refere à crença da existência do mundo independente do nosso conhecimento dele, assim como independente da nossa habilidade de processar a existência das coisas, da verdade e outros. b) $O$ realismo científico, que se trata da existência do mundo real independente das habilidades cognitivas humanas, havendo uma correspondência entre o mundo real e as teorias científicas sobre esse ele. c) $O$ realismo mundano que, diferentemente dos outros, não se relaciona a uma tradição filosófica, sendo essa classificação pertinente ao argumento laboviano de que uma linguística realista deve se focar no mundo cotidiano, em que pessoas "reais" vivem, atuam. Logo, a razão de a linguística ser o reflexo real dos fatos linguísticos dessas vidas.

Labov, segundo Figueroa, mantém a posição realista de que o contexto social é formado por fatos sociais que, mesmo não atuando sobre o indivíduo, não são por ele criados, o que possibilita a compreensão do fato social como "uma forma de comportamento, que: a) é geral na sociedade; b) exerce condicionamento sobre os indivíduos; c) esse condicionamento é peculiar em termos de geralmente ser inconsciente e, portanto, não poder agir diretamente" (LABOV, 1972a p. 72).

No que tange à aquisição do sistema gramatical e do sistema sócio-semiótico da língua, a autora retrata que Labov traça distinção entre esses sistemas, haja vista ele considerar a existência da aquisição de muitos estilos de discursos diferentes, mas não, a aquisição de muitas gramáticas diferentes.

Numa revisão dos cinquenta anos da linguística norte-americana, Labov recortou a história em dois períodos (1925-1955, 1955-1975), de modo a compreender os avanços possibilitados pelo estudo linguístico neles desenvolvidos, bem como reconhecer suas falhas empíricas, embora mantendo a estrutura formal já obtida (adaptado de Labov, 1975, p. 128, 129). Para Figueroa, Labov, ao reconhecer a contribuição do conhecimento de antes na construção do conhecimento de agora, adota uma noção positivista da ciência e, ao mesmo tempo, rejeita noções antipositivistas do desenvolvimento científico, como Kuhn (1962). A autora defende que o progresso científico se dá de forma cumulativa com um corpo crescente de conhecimento, conforme visão laboviana. Todavia, consoante ela aponta, Labov acaba por se contradizer, pois ao defender uma possível convergência entre os 
linguistas dos dois períodos - aqueles que descrevem a língua com base em dados objetivos e os que a descrevem baseado em dados reais - ele rejeita o ponto de vista antipositivista da não existência de uma única realidade linguística, o que impossibilita, pois, a convergência entre as duas frentes de estudiosos e/ou de conhecimentos.

Sob uma visão metateórica, Figueroa busca a base filosófica do pensamento de Labov, de modo a apontar que a metodologia laboviana apresenta nessa base uma ruptura de paradigma. Assim sendo, a autora traça analogias do estudo laboviano com os de Saussure e os de Chomsky, analogias relevantes que facultam compreender o quanto Labov é inigualável no modo de absorver, posicionar-se e fazer uso dos conhecimentos de teorias linguísticas já existentes.

Figueroa assevera que a oposição entre os linguistas incide na determinação do objeto de estudo da linguística, bem como no lócus da linguagem, muito embora o exame do funcionamento do sistema linguístico seja o alvo das hipóteses e análises dos três estudiosos. Quanto à teoria gerativa, Labov critica o fato de ela ter como objeto de estudo o conhecimento abstrato da regra da língua (gramática), pois a linguagem é um fato social e não individual. Para ele, a linguagem é de pertencimento da comunidade e são as relações sociais entre as distintas comunidades falantes que influenciam as mudanças linguísticas. Tem-se que o grande interesse de Labov é a questão metodológica, e não a teoria da língua. Ele quer soluções definitivas resultantes de um novo modo de se fazer linguística: através de dados empíricos das comunidades falantes.

No capítulo "Labov, Chomsky e os Fundamentos Empíricos da Linguística", Figueroa deixa clara a definição de Labov e de Chomsky como realistas, muito embora este apele ao realismo psicológico, porque seus dados correspondem ao funcionamento do cérebro e, desse modo, sua teoria é da estrutura da faculdade mental de linguagem. Já, Labov apela ao realismo mundano, haja vista seus dados corresponderem ao que as pessoas realmente fazem, caracterizando, portanto, sua teoria como da estrutura da linguagem à medida que ela é embutida na estrutura social. Conclui-se, assim, que o objeto de estudo laboviano e chomskyniano é distinto, tal como para eles também está em posições distintas o lócus da linguagem.

No que concerne à comunidade linguística, a autora se reporta à ideia de Labov considerar a língua como propriedade da comunidade e não do indivíduo, e, ao mesmo tempo, fala da imprecisão ao se definir comunidade linguística que, para Labov (1972a p. 158), refere-se a "um grupo que compartilha das mesmas normas em relação à língua".

Figueroa salienta que, segundo Labov, problemas teóricos ou diferenças entre análises antagônicas podem ser resolvidos por meio de informações empíricas e esclarece ter havido ganhos com a focalização da proposta laboviana no contexto social, essencialmente quanto à possibilidade de tratamento sistemático da empiria. Para ela, isso não deve ser interpretado como mais do que "o foco no contexto social não é uma tentativa de construir uma teoria sobre o papel do contexto social na língua; em vez disso, o contexto social é o lugar onde os dados são coletados".

Sobre os estilos e o vernáculo, Figueroa ressalta que Labov, toma este como de interesse da linguística, visto ser a "fala mais sistemática onde as relações 
fundamentais determinantes à evolução da linguística podem ser vistas com mais clareza"( Labov, 1972a, pág. 208), aqueles, por sua vez, em razão dos padrões gramaticais e fonológicos irregulares, com muita hipercorreção, nem todos são tomados como interessantes à linguística.

A autora remete-se ao capítulo "A Lógica do Inglês Não-standart" (1972) em que Labov discute a pureza e natureza direta da fala da classe operária, demonstrando assim, a natureza variável da língua em decorrência de fatores sociais.

Nesse sentido, Figueroa postula que a linguística de Labov se tornou sinônimo do estudo de variações e mudanças linguísticas, sendo seu trabalho sobre a variação influenciado pelo: descontentamento com a falta de base empírica; trivialização da variação linguística; descontentamento com a dialetologia por não observar a fala dos indivíduos. Crítica que se estende à teoria chomskyana por estudar o que as pessoas acham que fazem.

A língua não pode ser entendida como individual, ao contrário, ela é social. Labov discorda de Saussure, Chomsky e outros que defendem uma homogeneidade na língua, ignorando a heterogeneidade nela existente, de forma a considerarem a fala como caótica e desmotivada. Para o referido autor, a língua é um fato social e heterogêneo, logo, ele defende as variações linguísticas e não a língua como sendo homogênea e invariável.

Labov definiu uma variável sociolinguística como "aquela que é relacionada com alguma variável não-linguística do contexto social; do falante, a abordagem, a audiência, a situação, etc." (adaptado de Labov, 1972a, p. 237). Esclarece Figueroa que o tipo de contexto social descrito por Labov é mais típico daquele sugerido na etnografia da comunicação do que o usado em análise de variação, sendo, pois, estranho esse conceito, visto ele não o usar em seu trabalho.

Figueroa cita Cameron que fala da carência de definição de certos conceitos em Labov, como: norma e identidade; classe, etnia e gênero, para uma melhor explicação das variações (adaptado de Cameron, 1990, p. 81), o que significa que a variável sociolinguística é baseada em noções não explicadas de variáveis sociais.

No mais, a autora se remete aos três argumentos apresentados no capítulo, os quais se centram em: a) Labov ser visto como um realista científico. b) Labov ser visto como um positivista cujo interesse era a construção das bases empíricas da linguística. c) O posicionamento de Labov como participante da ciência normal e linguística, bem como faz alusão:

- ao aspecto social do sistema linguístico, esclarecendo o campo gerativista também se preocupar com ele, tanto que Paterman sugere a necessidade de ele se expandir para o mundo social;

- à tentativa de Labov de renovar a abordagem linguística saussuriana de ignorar a natureza social da língua e desconsiderar a fala na equação linguística de língua, língua e fala;

- à falha na tentativa de Labov de explicar a natureza social da linguagem, haja vista ele não incorporar as dimensões sociais da linguagem na sua teoria, o que se tivesse sido feito evitaria a polarização e fragmentação linguística. 
Desse modo, conclui-se que a leitura de Figueroa contribui, sobremaneira, para a releitura de Labov, ou seja, para a projeção de um novo/outro olhar sobre os pressupostos teóricos da Sociolinguística.

REFERÊNCIA:

FIGUEROA. Esther. Part Two: William Labov and Sociolinguistic Realism. In: . Sociolinguistic metatheory. Oxford: Pergamon, 1994. 